\title{
Correction to: Mental Health and Coping Strategies in Undergraduate Students During COVID-19 Pandemic
}

\section{Naiana Dapieve Patias ${ }^{1}\left[\begin{array}{l}(1) \\ \text { Jean Von Hohendorff }\end{array}\right.$ Pedro Augusto Flores ${ }^{2} \cdot$ Fabio Scorsolini-Comin ${ }^{3}$ (])}

Published online: 13 May 2021

(c) Associação Brasileira de Psicologia 2021

\section{Correction to: Trends in Psychology https://doi.org/10.1007/s43076-021-00069-z}

The following corrections need to be made to the published article:

- The title of the article was incorrect. It was updated to "Mental Health and Coping Strategies in Undergraduate Students During COVID-19 Pandemic"

- The word "postgraduates" was incorrectly included in the following sentence of the fourth paragraph of page 2: "These surveys indicate that undergraduates and postgraduates' students already suffer...". This sentence was updated to "These surveys indicate that undergraduate students already suffer...".

- The word "graduates" was incorrectly included in several sentences throughout the article. It was updated to "undergraduates" in the following sentences:

- Page 4, paragraph 1:

The original article can be found online at https://doi.org/10.1007/s43076-021-00069-z

Naiana Dapieve Patias

naipatias@hotmail.com

Jean Von Hohendorff

jhohendorff@gmail.com

Alisson Junior Cozzer

alisson.cozzer@imed.edu.br

Pedro Augusto Flores

pedro_augustof@hotmail.com

Fabio Scorsolini-Comin

fabio.scorsolini@usp.br

1 Universidade Federal de Santa Maria (UFSM), Santa Maria, Brazil

2 IMED, Passo Fundo, Brazil

3 Departamento de Enfermagem Psiquiátrica e Ciências Humanas da Escola de Enfermagem de Ribeirão Preto da Universidade de São Paulo (EERP-USP), São Paulo, Brazil 
"From this perspective, there is a need to develop Brazilian studies to compose a list of knowledge related to the theme of mental health of undergraduates in the context of the COVID-19 pandemic."

- Page 6, paragraph 4:

"When comparing groups of undergraduates from different types of Higher Education Institutions (G1-public, G2-private, or G3-community), the results indicated differences between public and private, and undergraduates from public institutions had higher scores on depression symptoms than those studying at private institutions, with an effect size of $0.18 . "$

- Page 13, paragraph 5:

"Regarding religiosity/spirituality, undergraduates who practice some religion presented lower scores in depression symptoms than those who do not practice it. These findings corroborate the scientific literature (de Souza et al. 2008)."

- Page 14, paragraph 2:

"Overall, undergraduates from public institutions usually belong to a lower socioeconomic status. Therefore, knowing that income has an impact on mental health (de Duarte et al. 2020; Marinho Alves and Rodrigues 2010; Nogueira and Sequeira 2017), such a result is not unexpected."

- Page 15, paragraph 7:

"The results of this study make it possible to conclude that the pandemic seems to affect the undergraduates unanimously. However, some factors are important in this discussion."

- The amounts in US dollars of the minimum wage in Brazil were incorrect on page 4, paragraph 4 . The amounts were corrected in the following sentence:

"Most of the students (30\%) declared a family income of two to four minimum wages (until US \$ 805.54), and $28 \%$ income of until two minimum wages (\$ 402.77)”.

- The first sentence of the first paragraph on page 6 incorrectly informed that "normality tests (...) were performed, which demonstrated the normal distribution of the data". This sentence was updated to:

"At first, normality tests (Kolmogorov-Smirnov and Shapiro-Wilk) were performed, and the normal distribution of data was not found."

The original article has been corrected. 